\title{
CORRECTION
}

\section{Correction to: Rarefied gas flow through a rough channel into a vacuum}

\section{O. Sazhin ${ }^{1}$}

Published online: 20 April 2020

(c) Springer-Verlag GmbH Germany, part of Springer Nature 2020

\section{Correction to:}

Microfluidics and Nanofluidics (2020) 24:27

https://doi.org/10.1007/s10404-020-2330-y

Publisher's Note Springer Nature remains neutral with regard to jurisdictional claims in published maps and institutional affiliations.

In Table 3, there is a mistype in one cell [first row, fifth column]. Here, at $l / h=1, \delta=0$ and $\alpha=45^{\circ}$, the mass flow rate should be $Q^{*}=0.6100$ (not 0.6010 ). As a result, Fig. 2a should be different, i.e. the minimum $Q^{*}$ at $\delta=0$ and $\alpha=45^{\circ}$ disappears. Below is the correct version of Fig. 2a.

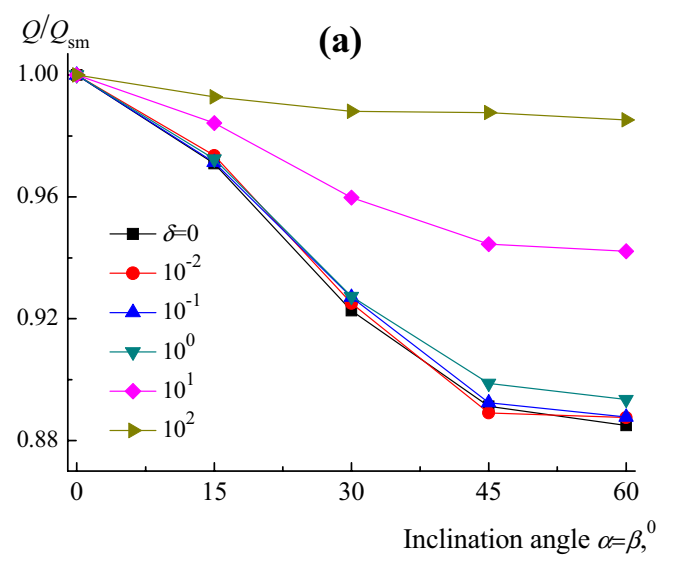

Fig. 2 a The relative gas flow rate $Q / Q_{\text {sm }}$ through a modeled rough channel into a vacuum, as a function of inclination angle $\alpha$ and rarefaction parameter $\delta$ for the length to height ratio $l / h=1$

The original article can be found online at https://doi.org/10.1007/ s10404-020-2330-y.

O. Sazhin

oleg.sazhin@urfu.ru

1 Ural Federal University, Lenin av. 51, Ekaterinburg 620000, Russia 